[14] J. J. Hopfield, "Theory of the contribution of excitons to the complex dielectric constant of crystals," Phys. Rev., vol. 112, pp. 1555-1567, 1958.

[15] D. C. Reynolds and T. C. Collins, Excitons: Their Properties and Uses. New York: Academic, 1981.

[16] R. L. Liboff, Introductory Quantum Mechanics. Oakland, CA: Holden Day, 1980.
[17] R. H. Pantell and H. E. Puthoff, Fundamentals of Quantum Electronics. New York: Wiley, 1969.

[18] R. J. Elliot, "Intensity of optical absorption by excitons," Phys. Rev., vol. 108, pp. 1384-1389, 1957.

[19] C. Benoit à la Guillaume, J. M. Debever, and F. Salvan, "Radiative recombination in highly excited CaS," Phys. Rev., vol. 177, pp. 567-580, 1969.

\title{
SMMW Laser Emission and Frequency Measurements in Doubly-Deuterated Methyl Fluoride $\left(\mathrm{CHD}_{2} \mathrm{~F}\right)$
}

\author{
MARY S. TOBIN
}

\begin{abstract}
Submillimeter wave laser action is reported in $\mathrm{CHD}_{2} \mathrm{~F}$ on 17 "parent" transitions plus three cascade lines. Accurate heterodyne frequency measurements are reported for nine lines. Useful output powers of greater than $1 \mathrm{~mW}$ were observed for several lines. The strongest line, which is at $384.3 \mu \mathrm{m}$, is particularly significant because of its potential as a local oscillator for the $385 \mu \mathrm{m} \mathrm{D} D_{2} \mathrm{O}$ laser.
\end{abstract}

$\mathrm{S}$ UBMILLIMETER wave (SMMW) laser action obtained by the technique of optical pumping was originally [1] demonstrated with methyl fluoride $\left({ }^{12} \mathrm{CH}_{3} \mathrm{~F}\right)$. Since that time SMMW laser operation has been obtained from numerous other gases, including three other isotopic forms of methyl fluoride, ${ }^{13} \mathrm{CH}_{3} \mathrm{~F}$ [2], ${ }^{12} \mathrm{CD}_{3} \mathrm{~F}$ [3] , and ${ }^{13} \mathrm{CD}_{3} \mathrm{~F}$ [4]. In this letter, optical pumping of doubly-deuterated methyl fluoride $\left({ }^{12} \mathrm{CHD}_{2} \mathrm{~F}\right)$ is described. Seventeen pump lines were found to produce SMMW laser output on a total of 20 lines, including three cascade lines. Accurate heterodyne frequency measurements are reported for nine lines. In addition to obtaining spectroscopic information which is valuable for analysis of the excited vibrational states, we have also found that several $\mathrm{CHD}_{2} \mathrm{~F}$ lines are at the milliwatt power level, thereby adding to the number of useful sources in this spectral region.

$\mathrm{CHD}_{2} \mathrm{~F}$ is a near-symmetric top molecule with Ray's asymmetry parameter $\kappa=-0.970[5]$. Low-resolution infrared spectroscopy indicates several absorption bands in the $\mathrm{CO}_{2}$ laser region. These include $\nu_{5}$ at $1050 \mathrm{~cm}^{-1}, \nu_{4}$ at $1092 \mathrm{~cm}^{-1}$, $\nu_{6}$ at $965 \mathrm{~cm}^{-1}$, and $\nu_{9}$ at $897 \mathrm{~cm}^{-1}$ [5]. There are numerous absorption coincidences of $\mathrm{CHD}_{2} \mathrm{~F}$ with the $\mathrm{CO}_{2}$ laser, as can be seen from the optoacoustical spectrum (Fig. 1). This spectrum was obtained with a microphone mounted inside the cavity and used to select possible pump lines. It can be seen from the $\mathrm{CO}_{2}$ tuning profile that the $9 R$ lines are poorly

Manuscript received June 7, 1983; revised August 24, 1983.

The author is with Electronics Research and Development Command, Harry Diamond Laboratories, Adelphi, MD 20783. resolved, which limits the usefulness of the $9 R$ portion of the optoacoustic spectrum.

Two separate SMMW lasers were used in this experiment. The primary laser [3] contains a metallic $25.4 \mathrm{~mm}$ diameter waveguide resonator which is $90 \mathrm{~cm}$ long and has a $3.5 \mathrm{~mm}$ holecoupled output mirror. This laser provides the best performance for the longer wavelength lines and was used for the power and frequency measurements. A second resonator employing a $31 \mathrm{~mm}$ diameter Pyrex tube was used to obtain relative polarizations. A maximum of about $15 \mathrm{~W} \mathrm{CW}$ power for the strongest $\mathrm{CO}_{2}$ laser pump lines is coupled into the SMMW cavity for optical pumping. The $\mathrm{CHD}_{2} \mathrm{~F}$ gas sample, of estimated isotopic purity greater than 95 percent [6], was prepared by Prof. D. F. Eggers of the University of Washington.

The pump lines and associated SMMW laser wavelengths measured with a micrometer-tuned diplexer [7] with an accuracy within 0.2 percent are listed in Table I. For those lines which we were able to heterodyne, the calculated vacuum wavelengths are listed rather than the less accurate interferometric values. The frequency measurements were made by mixing the laser output with the harmonics of a phase-locked $K a$-band klystron in a Schottky barrier diode which was supplied by Lincoln Laboratory. The experimental arrangement is indicated in Fig. 2. The klystron is locked with the aid of a $100 \mathrm{MHz}$ crystal oscillator signal which is multiplied to the $3.5 \mathrm{GHz}$ region, where it is counted and harmonically mixed with the klystron frequency. The klystron signal, which can be locked at discrete frequencies in the $34-37 \mathrm{GHz}$ range, reaches the diode through a coaxial fitting. Beat notes in the range of 0 $8 \mathrm{GHz}$, corresponding to the range of our IF amplifiers, are displayed on the spectrum analyzer. An EIP model 548 counter is used to accurately measure the beat frequency and to determine the locked klystron frequency. The laser frequencies listed in Table I represent the center of the laser tuning profile as visually determined on the spectrum analyzer as the cavity 


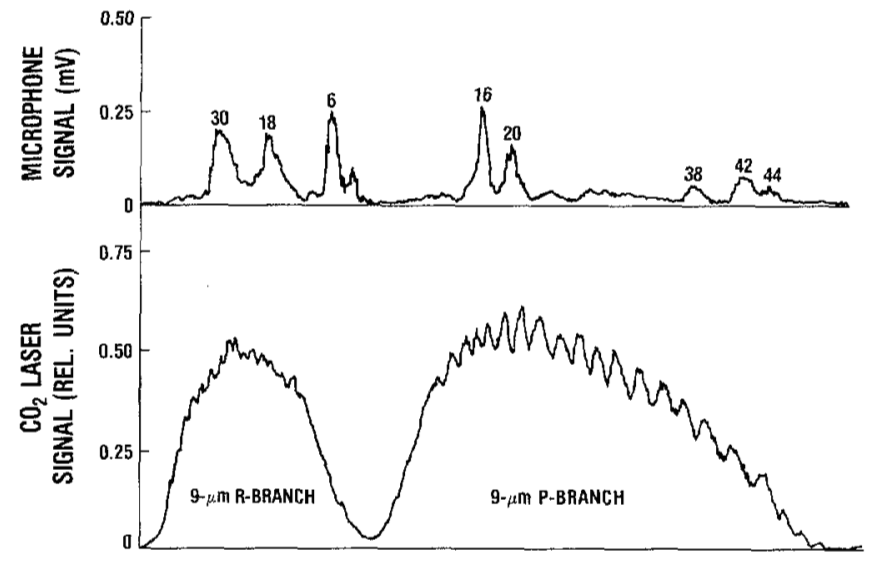

$\mathrm{CO}_{2}$ LASER PROFILE

(a)

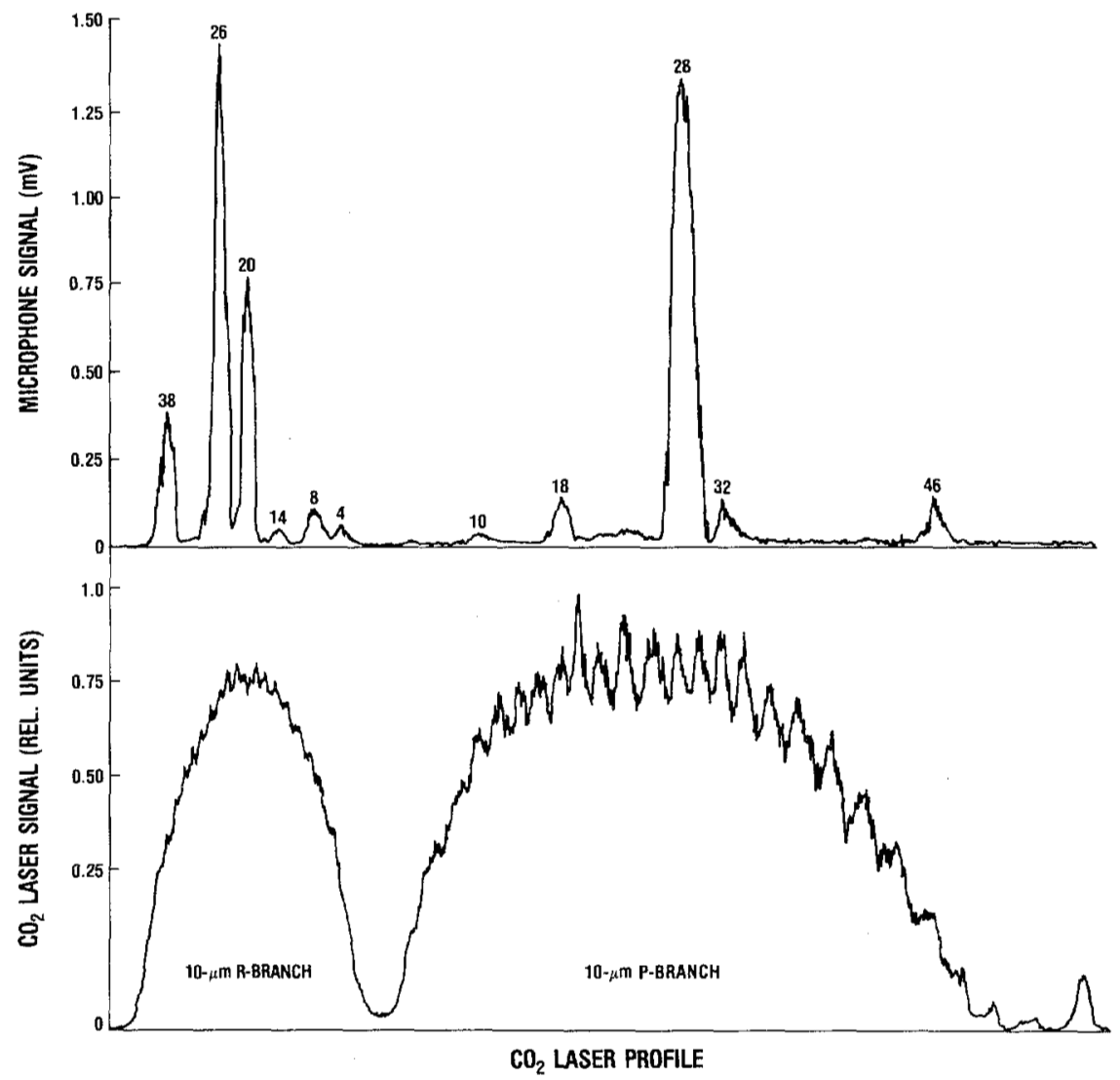

(b)

Fig. 1. Microphone-detected absorption of $\mathrm{CHD}_{2} \mathrm{~F}$ at $460 \mathrm{~m}$ torr. (a) 9 $\mu \mathrm{m} \mathrm{CO}_{2}$ pump lines. (b) $10 \mu \mathrm{m} \mathrm{CO}_{2}$ pump lines. The numbers refer to the $\mathrm{CO}_{2}$ laser lines.

length was tuned. In $\mathrm{CHD}_{2} \mathrm{~F}$ the tuning profile was about 4$6 \mathrm{MHz}$ wide; however, the measurements of the center were generally reproducible within $\pm 0.7 \mathrm{MHz}$. We were unable to heterodyne the weaker lines above $900 \mathrm{GHz}$.

The cascade lines were all discovered in the heterodyne mode. The first cascade line was found by accident when a 43.25 $\mathrm{GHz}$ signal, which corresponds to the beat produced by the simultaneous oscillation of the two lines pumped by the $10 P 28 \mathrm{CO}_{2}$ line, was detected. The cascade lines associated with the $10 R 20$ and $10 R 26$ pump lines were subsequently obtained by searching for frequencies near $43.3 \mathrm{GHz}(\simeq 2 B)$ below those of the "parent" transitions. An attempt to find the cascade for the strong $10 R 38$ pumped line was unsuccessful. These frequencies should be very valuable in the analysis of the associated spectral bands.

In Table I, one of the pump lines is attributed to the $P$-branch transition of the $\mathrm{CO}_{2}$ laser $01^{\prime} 1$ to $11^{\prime} 0$ hot band. The question mark after the pump indicates our uncertainty in distinguish- 
TABLE I

$\mathrm{CHD}_{2}$ F LASER RESULTS

\begin{tabular}{|c|c|c|c|c|c|c|}
\hline $\begin{array}{l}\mathrm{CO}_{2} \\
\mathrm{Pump} \\
\text { Line }\end{array}$ & $\begin{array}{c}\text { Pump } \\
\text { Wavelength } \\
(\mu \mathrm{m})\end{array}$ & $\begin{array}{c}\text { SMMW } \\
\text { Wavelength } \\
\lambda(\mu \varpi)\end{array}$ & $\begin{array}{c}\text { Heterodyne } \\
\text { Measurement } \\
v(\text { MH } z)\end{array}$ & $\begin{array}{c}\text { Relative } \\
\text { Polarization }\end{array}$ & $\begin{array}{l}\text { Pump } \\
\text { Mode }\end{array}$ & $\begin{array}{l}\text { Relative } \\
\text { Signal } \\
\text { Strength }^{b}\end{array}$ \\
\hline H BP25? & 11.038 & $277 \pm 5^{c}$ & - & - & $\mathrm{C}$ & $\mathrm{vw}$ \\
\hline $10 \mathrm{P} 48$ & 10.910 & 204.0 & - & $\|$ & $\mathrm{c}$ & w \\
\hline $10 \mathrm{P} 46$ & 10.885 & $984.7953^{\mathrm{d}}$ & 304421.1 & - & $\mathrm{Cw}$ & M \\
\hline \multirow[t]{2}{*}{$10 \mathrm{P} 28$} & 10.675 & $384.3190^{\mathrm{d}}$ & 780061.5 & $\|$ & $\mathrm{CW}$ & vs \\
\hline & $406.8778^{d}$ & 736812.0 & - & $\mathrm{CW}$ & - & \\
\hline \multirow[t]{2}{*}{$10 \mathrm{R} 20$} & 10.247 & $862.5443^{\mathrm{d}}$ & 347568.0 & $\|$ & ow & M \\
\hline & $986.0702^{d}$ & 304027.5 & $-\cdots$ & $\mathrm{CW}$ & - & \\
\hline \multirow[t]{2}{*}{$10 \mathrm{R} 26$} & 10.207 & $691.2505^{d}$ & 433695.8 & $\|$ & $C W$ & vs \\
\hline & $768.0117^{d}$ & 390348.8 & - & CW & - & \\
\hline $10 \mathrm{R} 38$ & 10.147 & $435.4265^{d}$ & 688503.0 & $\|$ & $\mathrm{CW}$ & s \\
\hline $9 \mathrm{P} 50$ & 9.836 & - & - & - & c & wW \\
\hline $9 P 44$ & 9.773 & 301.0 & - & $\|$ & $\mathrm{CW}$ & W \\
\hline $9 \mathrm{P} 42$ & 9.753 & 193.4 & - & 11 & CW & $w$ \\
\hline $9 \mathrm{P} 34$ & 9.676 & 163.3 & - & $\|$ & $\mathrm{CW}$ & W \\
\hline $9 \mathrm{P} 16$ & 9.520 & 232.0 & - & " & $C W$ & M \\
\hline $9 \mathrm{P} 10$ & 9.473 & 231.0 & - & $\|$ & $\mathrm{CW}$ & $\omega$ \\
\hline 986 & 9.354 & $375.4072^{\mathrm{d}}$ & 798579.5 & $\|$ & $c$ & M \\
\hline $9 \mathrm{R} 16$ & 9.294 & 260.0 & - & $\|$ & $\mathrm{CW}$ & $M$ \\
\hline 9R20 & 9.271 & 285.1 & - & $\|$ & $\mathrm{CW}$ & M. \\
\hline 9R30 & 9.220 & 292.7 & - & $\|$ & $\mathrm{CW}$ & M \\
\hline
\end{tabular}

a $\mathrm{CW}$, true $\mathrm{CW}$; C, electrically chopped mode.

b $\mathrm{vS}>5 \mathrm{~mW} ; \mathrm{S} \simeq 0.1-5 \mathrm{~mW} ; \mathrm{M} \simeq 10-100 \mu \mathrm{W} ; \mathrm{W} \leq 10 \mathrm{\mu W}$.

$c$ Wavelength of this very weak line estimated from cavity scan.

d Calculated from measured frequency with $\mathrm{c}=299792458 \mathrm{~m} / \mathrm{s}$.

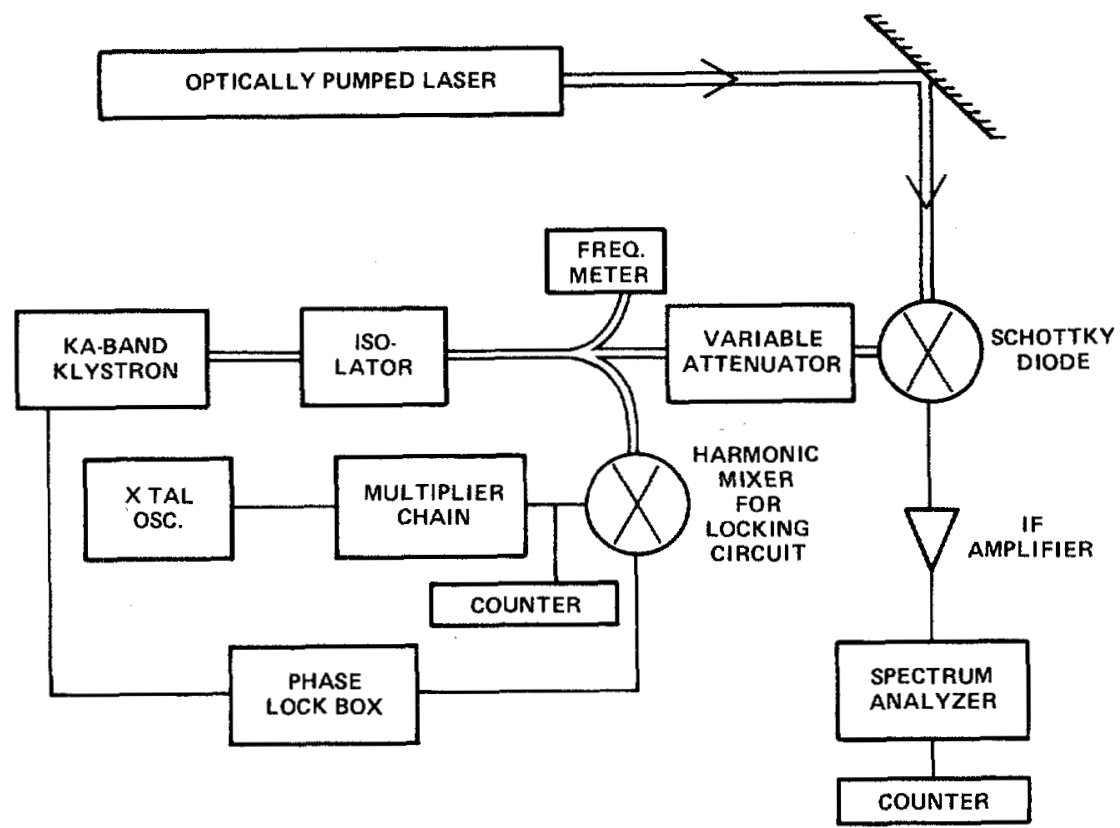

Fig. 2. Schematic of experimental setup.

ing these weak lines with the Optical Engineering spectrum analyzer. The 10P28 pump line produced very strong output at $384.3 \mu \mathrm{m}$. In the previous $\mathrm{CD}_{3} F$ results [3], weak emission at $384.7 \pm 0.5 \mu \mathrm{m}$ with the same $10 P 28$ pump was reported; apparently, this result can be attributed to a small amount of isotopic impurity of $\mathrm{CHD}_{2} \mathrm{~F}$ in the $\mathrm{CD}_{3} \mathrm{~F}$ sample.
In Table I, the signal strengths are rated qualitatively based on the Golay-detector signal. Typical pressures were in the 100-120 mtorr range and were not optimized for each line. In Table II the power measurements for the stronger lines are given, along with the results for some other well-known gases in the same relatively short $(90 \mathrm{~cm})$ unoptimized resonator. 
TABLE II

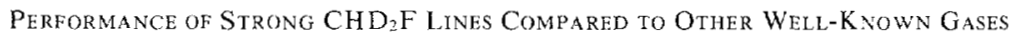

\begin{tabular}{|c|c|c|c|c|c|c|}
\hline \multirow[t]{2}{*}{ GAS } & \multirow[t]{2}{*}{$\lambda(\mu m)$} & \multirow{2}{*}{$\begin{array}{l}\text { Pressure } \\
\text { (mTorr) }\end{array}$} & \multirow{2}{*}{$\begin{array}{l}\mathrm{CO}_{2} \text { Purmp } \\
\text { Line }\end{array}$} & \multirow{2}{*}{$\begin{array}{c}\text { Pump }{ }^{\mathrm{a}} \\
\text { Power }(W)\end{array}$} & \multicolumn{2}{|c|}{ SMMW Power ${ }^{b}$ (mw) } \\
\hline & & & & & Direct & Corrected \\
\hline $\mathrm{CHD}_{2} \mathrm{~F}$ & 384.3 & 104 & $10 P 28$ & 13.5 & 6.0 & 12.0 \\
\hline $\mathrm{CHO}_{2} \mathrm{~F}$ & 691.3 & 110 & $10 \mathrm{R} 26$ & 10 & 3.0 & 5.5 \\
\hline $\mathrm{CHD}_{2} \mathrm{~F}$ & 435.4 & 114 & $10 R 38$ & 7 & 1.4 & 2.8 \\
\hline $\mathrm{CH}_{3} \mathrm{~F}$ & 496 & 50 & $9 P 20$ & 9 & 1.4 & 2.8 \\
\hline $\mathrm{CH}_{3} \mathrm{OH}$ & 570 & 124 & $9 P 16$ & 10 & 3.8 & 7.6 \\
\hline
\end{tabular}

a Pump power coupled into SMMW resonator

b Measurements taken with Scientech 362; corrected powers are estimated using Scientech

calibration data from Ref. 9.

In conclusion, several of the $\mathrm{CHD}_{2} \mathrm{~F}$ lines appear to be very useful and would be expected to produce tens of milliwatts in optimized cavities. The strongest line at $384.3 \mu \mathrm{m}$ satisfies a special need for a strong $\mathrm{CW}$ laser in this region. In particular, since this line falls about $1 \mathrm{GHz}$ above the frequency of the $\mathrm{D}_{2} \mathrm{O}$ line at $779 \mathrm{GHz}[8]$, it should be very useful as a local oscillator in plasma diagnostics.

\section{ACKNOWLEDGMENT}

The author thanks D. F. Eggers from the University of Washington for supplying the $\mathrm{CHD}_{2} \mathrm{~F}$ sample and suggesting this gas. The author is also grateful to H. R. Fetterman, currently at the University of California, and B. J. Clifton of Lincoln Laboratory for supplying the Schottky diode. Additional thanks go to R. D. Suneram of the National Bureau of Standards, A. Krall of the Naval Surface Weapons Center, and P. Schwarz of the Naval Research Laboratories for loan of equip. ment vital for the heterodyne measurements.

\section{REFERENCES}

[1] T. Y. Chang and T. J. Bridges, "Laser action at 452,496 , and 541 $\mu \mathrm{m}$ in optically pumped $\mathrm{CH}_{3} \mathrm{~F}$," Opt. Commun., vol. 1, pp. 423426,1970 .
[2] T. Y. Chang and J. D. McGee, "Millimeter and submillimeter wave laser action in symmetric top molecules optically pumped via parallel absorption bands," Appl. Phys. Lett., vol. 19, pp. 103$105,1971$.

[3] M. S. Tobin, J. P. Sattler, and G. L. Wood, "Optically pumped $\mathrm{CD}_{3} \mathrm{~F}$ submillimeter-wave laser," Opt. Lett., vol. 4, pp. 384-386, 1979; see also Conf. Dig. 4th Int. Conf. Infrared Millimeter Waves, IEEE Cat. 79C4 1384-TMTT, 1979, pp. 209-210.

[4] M. S. Tobin and R. D. Felock, "Submillimeter wave laser emission in optically pumped methyl fluoride $-{ }^{13} \mathrm{CD}_{3} \mathrm{~F}$," IEEE J. Quantum Electron., vol. QE-17, pp. 825-826, 1981.

[5] J. R. Riter, Jr. and D. F. Eggers, Jr., "Fundamental vibrations and force constants in the partially deuterated methyl halides," $J$. Chem. Phys., vol. 44, pp. 745-758, 1966.

[6] D. F. Eggers, Dep. Chem., Univ. Washington, Seattle, WA, private communication.

[7] N. R. Erickson, "A directional filter diplexer using optical techniques for millimeter to submillimeter wavelengths," IEEE Trans. Microwave Theory Tech., vol. MTT-24, pp. 865-866, 1977.

[8] H. R. Fetterman, P. E. Tannenwald, C. D. Parker, J. Meingailis, R. C. Williamson, P. Woskoboinikow, H. C. Praddaude, and W. J. Mulligan, "Real-time spectral analysis of far-infrared laser pulses using a SAW dispersive delay line," Appl. Phys. Lett., vol. 34, pp. 123-125, 1979.

[9] F. B. Foote, D. T. Hodges, and H. B. Dyson, "Calibration of power and energy meters for the far infrared/near millimeter wave spectral region," Int. J. Infrared Millimeter Waves, vol. 2, pp. 773782,1981 . 